\title{
Influence of Mild Cognitive Impairment, Depression, and Anxiety on the Quality of Life of Patients with Parkinson Disease
}

\author{
Daniel Wiesli Antonia Meyer Peter Fuhr Ute Gschwandtner \\ Department of Neurology, University Hospital Basel, Basel, Switzerland
}

\section{Keywords}

Quality of life · Parkinson disease $\cdot$ Neuropsychiatric symptoms · Mild cognitive impairment

\begin{abstract}
Background: Neuropsychiatric symptoms (NPS) and mild cognitive impairment (MCI) are common in Parkinson disease (PD) and have a negative impact on the patient's quality of life (QoL). We aim to describe the effect of NPS and MCI on each other and on QoL. Methods: Sixteen MCI and 37 non-MCI PD patients completed different self-assessment questionnaires including the Parkinson's Disease Questionnaire (PDQ-39), the Beck Depression Inventory $(\mathrm{BD})$, the Beck Anxiety Inventory (BAI), and the Self-Report Manic Inventory (SRMI). Linear regression with stepwise elimination was used to select the significant predictors of QoL and to control for confounding factors. Results: The significant linear regression model $\left(R^{2}=0.68\right.$, $p \leq 0.01)$ revealed significant effects of $\mathrm{MCI}(p=0.03)$, BDI $(p \leq 0.01)$, BAI $(p \leq 0.01)$, age $(p=$ $0.03)$, a trend of SRMI $(p=0.06)$, and disease duration ( $p=0.08)$ on QoL. Conclusions: MCI, anxiety, depression, and age decrease QoL in patients with PD. NPS has the main influence in the prediction of $\mathrm{QoL}$ in patients with $\mathrm{PD}$, whereas $\mathrm{MCI}$ is only of minor importance.
\end{abstract}

\section{Introduction}

Parkinson disease (PD) is well known for its motor symptoms such as rigor, tremor, postural instability, and bradykinesia. However, there are also non-motor symptoms (NMS), which have a strong impact on quality of life (QoL), such as constipation, olfactory disturbances, and obsessional behavior [1-8]. The economic burden for society is comparable to that of strokes or heart failures $[9,10]$.

Furthermore, $10-50 \%$ of patients with PD are affected by depression and anxiety [11]. Depression and anxiety are described as neuropsychiatric symptoms (NPS) and, as such, from 
a subgroup of NMS [1]. Some NPS such as mania, obsessional behavior, and hallucinations are related to dopaminergic treatment $[1,12]$.

The core symptoms of mania are a decreased need for sleep, attention deficits, an increased urge of compulsive speech hyperactivity, and inappropriate behavior in any further situation [13].

Obsessive-compulsive disorder (OCD) is characterized by obsessive thoughts and compulsive acts. Such obsessive thoughts for instance refer to be consumed by an idea, an impulse, or an imagination without the ability to resist these [13].

Turning to depression, which is marked by a loss of interests, joylessness, low spirit, increased fatigability, and a reduced urge, cross-sectional studies show that around $40 \%$ of patients with PD suffer from depression [14-18]. Further, by affecting cognitive abilities and basic life skills of PD patients, depression may not only concern PD patients alone but also their relatives regarding the reduction of their QoL [13, 19-21].

Anxiety disorders including general anxiety disorders and panic attacks, which in other words may be defined as an inexplicable anxiety response to any situation or place [13], may affect up to $40 \%$ of PD patients [22, 23]. Notably, anxiety disorders and depression can predate the motor symptoms of PD [24, 25].

Mild cognitive impairment (MCI) is a common symptom even in newly diagnosed drugnaive PD patients [26-30] and is also associated with reduced QoL [31]. Therefore, the present study is focusing on specific changes of QoL in PD patients suffering from MCI. Former studies analyzed this relation but did not focus on the group of MCI patients, NPS, and their reduction in QoL. Whilst the connection between NPS and MCI remains debatable $[32,33]$, the effect of NMS in association with MCI on QoL in PD remains unexplored to this date. Further, in contrast to the study by Monastero et al. [32], which may seem similar to this study here, we examined depression, anxiety, and QoL separately and in more detail. Additionally, we did not split the MCI patients into different subgroups. Moreover, we examined the relative importance of the predictors to achieve a better understanding of the effects of MCI and NPS and their influence on QoL. Our hypothesis was that reduced cognition in PD patients may influence NPS and QoL.

For our study we used self-assessment questionnaires and cognitive tests to gather information about NPS, QoL, and cognition. Our aim was to examine the main effects of depression, anxiety, OCD, mania, $\mathrm{MCI}$, and other confounding factors and their importance for QoL of PD patients.

\section{Methods}

\section{Sample}

We included 53 patients with PD fulfilling the criteria of the British Brain Bank [34]. The patients were participants of a cognitive training study of the University Hospital Basel (Department of Clinical Neurophysiology) [35]. Patients were recruited between May 2011 and March 2013 either via published advertisement or via the Movement Disorders Clinic of the University Hospital of Basel. Patients were excluded if (a) they had insufficient knowledge of the German language, (b) they had a Mini-Mental State Examination (MMSE) score $\leq 24$, (c) they had an alcohol or drug dependency, (d) more than 2 questionnaires were not sufficiently fulfilled or missed, or (e) they suffered from other severe neurological conditions. We also excluded patients if they had more than 3 incomplete test criteria within the tests for the MCI classification. 
Standard Protocol Approvals, Registrations, and Patient Consents

The study was approved by the local ethics committee (Ethikkommission beider Basel, ref. No.: 135/11). All participants were fully informed of the nature of the study and gave their written informed consent.

\section{Psychiatric and Psychological Assessment}

Depression

We used the German version of the Beck Depression Inventory II (BDI) [36] to detect symptoms of depression. This self-assessment questionnaire consists of 21 questions with 4 possible answers ranging from 0 (e.g., "I don't have any thoughts of killing myself") to 3 (e.g., "I would kill myself if I had the chance") regarding the Likert scale. Total scores could range between 0 and 63 . Please note that a higher point value may be an indication for more severe depression, respectively.

Anxiety

Symptoms of anxiety were measured with the German version of the self-assessment scale Beck Anxiety Inventory (BAI) [37]. This questionnaire consists of 21 questions, which are evaluated on a four-point Likert scale ranging from 0 (not at all) to 3 (severely - "it bothered me a lot"). The total score may range between 0 and 63 . Please note that higher values indicate more severe anxiety, respectively.

Compulsion

We used the German version of the Obsessive-Compulsive Inventory-Revised (OCI-R) [38] to detect OCD. The scale consists of 18 items, which are valued on a five-point Likert scale, ranging from zero (not at all) to four (extremely). The total score may range between 0 and 72 , increasing values refer to more severe anxiety.

Mania

To measure the symptoms of mania, we administered the German version of the SelfReport Manic Inventory (SRMI) consisting of 48 items. Each item is a statement such as (e.g., "I run into debt") and the patient replies whether it applies or not. The total score ranges from 0 to 48 , whilst higher values indicate a more severe obsession, respectively $[39,40]$.

Quality of Life

We used the German version of the Parkinson's Disease Questionnaire (PDQ-39) [41, 42] to assess the patients' QoL. This self-assessment questionnaire consists of 39 items, which are evaluated on a five-point Likert scale, ranging from 0 (never) to 4 (always). Eight dimensions are used to describe the QoL.

For our analyses we used the PDQ-39 Summary Index (PDQ-39SI) [41, 43], where the 8 dimensions are summarized as 1 score. This score is between 0 and 100, giving an overview of the QoL in PD, whereas a higher score refers to a poorer QoL.

Criteria for MCI

MCI classification was made according to the level II criteria of the movement society task force [44].

Confounding Factors

Confounding factors include gender, levodopa dose per day (LEDD according to Tomlinson et al. [45]), age, disease duration, motor impairment, level of education in years, and the 
Table 1. Demographics of cognitively normal PD and PD-MCI patients

\begin{tabular}{lccl}
\hline & $\begin{array}{l}\text { PD } \\
(n=37)\end{array}$ & $\begin{array}{l}\text { PD-MCI } \\
(n=16)\end{array}$ & $\begin{array}{l}\text { Significance } \\
\text { (Mann-Whitney) }\end{array}$ \\
\hline Age, years & $66 \pm 8.4$ & $68 \pm 7.2$ & $\mathrm{~ns}$ \\
Female & $15(40.54)$ & $4(25.00)$ & $\mathrm{ns}$ \\
Male & $22(59.46)$ & $12(75.00)$ & $\mathrm{ns}$ \\
Education, years & $15 \pm 2.8$ & $15 \pm 3.3$ & $\mathrm{~ns}$ \\
MMSE, points & $29 \pm 0.9$ & $28 \pm 1.6$ & $\mathrm{~ns}$ \\
Disease duration, years & $8 \pm 4.9$ & $8 \pm 5.4$ & $\mathrm{~ns}$ \\
UPDRS III, points & $16 \pm 11.4$ & $14 \pm 11.1$ & $\mathrm{~ns}$ \\
LEDD, mg/day & $721 \pm 541$ & $827 \pm 531.3$ & $\mathrm{~ns}$ \\
\hline
\end{tabular}

Values are shown as $n(\%)$ or mean \pm standard deviation. ns, not significant.

cognitive status. The severity of motor impairment was measured using the Unified Parkinson Disease Rating Scale (UPDRS III) [46] by trained neurologists. Cognitive status was compiled by using the MMSE [47].

\section{Statistical Analyses}

For statistical analysis we used RStudio Version 0.98.1103 for Macintosh [48]. A level of $p<0.05$ was regarded as statistically significant.

We calculated Spearman's rank correlation to analyze the intercorrelation between all evaluated NPS, separately for patients with and without MCI. A Mann-Whitney U test was administered to examine differences between subgroups of the PDQ-39, PDQ-39-SI, the selfassessment questionnaires as well as the confounding factors in patients with and without $\mathrm{MCI}$. To account for multiple testing, we used the Bonferroni correction. A linear regression model with Akaike Information Criterion (AIC) with backwards elimination [49] was applied to select the relevant predictors of QoL. The analyses were performed using age, gender, BDI, BAI, OCI-R, SRMI, disease duration, education, UPDRS III, LEDD, and cognitive status (MCI and non-MCI) as potential predictors for the QoL score. Stepwise backwards elimination was used to consecutively eliminate nonpredictive variables. The relative importance of the predictors was calculated with the package relaimpo [50] in R.

\section{Results}

\section{Sample}

According to our self-assessment questionnaires, in our sample, $32 \%$ of patients suffered from mild depression, 36\% from mild anxiety, 13\% from moderate anxiety, $4 \%$ from severe anxiety, $17 \%$ from OCD, and $6 \%$ from mania. Key numbers from the sample population are listed in Table 1, whilst Table 2 depicts a detailed register of the results and the cutoffs from the psychiatric and psychological assessments.

\section{Correlations between the NPS and QoL}

For patients with and without MCI each self-assessment questionnaire showed a significant correlation with QoL (Table 3). There were significant correlations between the different psychological self-assessment questionnaires. 
Table 2. Performance of cognitively normal PD and PD-MCI patients across tests

\begin{tabular}{|c|c|c|c|}
\hline & $\begin{array}{l}\mathrm{PD} \\
(n=37)\end{array}$ & $\begin{array}{l}\text { PD-MCI } \\
(n=16)\end{array}$ & $\begin{array}{l}\text { Significance } \\
\text { (Mann-Whitney) }\end{array}$ \\
\hline BDI II & $7 \pm 4.1$ & $7 \pm 3.9$ & ns \\
\hline Minimal depression (0-9) & $23(62)$ & $12(75)$ & ns \\
\hline Mild depression (10-18) & $13(35)$ & $4(25)$ & ns \\
\hline Moderate depression (19-29) & 0 & 0 & - \\
\hline Severe depression (30-63) & 0 & 0 & - \\
\hline NA & $1(3)$ & 0 & - \\
\hline BAI & $10 \pm 8$ & $8 \pm 6.3$ & ns \\
\hline Minimal level of anxiety (0-7) & $17(46)$ & $7(44)$ & ns \\
\hline Mild anxiety (8-15) & $11(30)$ & $8(50)$ & ns \\
\hline Moderate anxiety (16-25) & 7 (19) & 0 & - \\
\hline Severe anxiety (26-63) & $1(3)$ & $1(6)$ & ns \\
\hline NA & $1(3)$ & 0 & - \\
\hline OCI-R & $10 \pm 6.6$ & $7 \pm 7.4$ & \\
\hline Non-compulsivity $(<18)$ & $30(81)$ & $14(87.5)$ & ns \\
\hline Compulsivity $(\geq 18)$ & 7 (19) & $2(12.5)$ & ns \\
\hline NA & 0 & 0 & - \\
\hline SRMI & $4 \pm 3.9$ & $4 \pm 6.1$ & ns \\
\hline Non-mania $(<14)$ & $34(92)$ & $15(94)$ & ns \\
\hline Mania $(\geq 14)$ & $2(5)$ & $1(6)$ & ns \\
\hline NA & $1(3)$ & 0 & - \\
\hline PDQ-39SI & $19 \pm 9.5$ & $24 \pm 12.3$ & ns \\
\hline Mobility & $19 \pm 17.3$ & $28 \pm 19.7$ & ns \\
\hline Activities of daily living & $22 \pm 18.7$ & $26 \pm 16.6$ & ns \\
\hline Emotional well-being & $21 \pm 17.6$ & $20 \pm 11.3$ & ns \\
\hline Stigma & $10 \pm 10.3$ & $21 \pm 16.6$ & ns \\
\hline Social support & $5 \pm 9.3$ & $9 \pm 14.6$ & ns \\
\hline Cognitions & $27 \pm 14.6$ & $32 \pm 16.4$ & ns \\
\hline Communication & $17 \pm 18.5$ & $24 \pm 23.3$ & ns \\
\hline Bodily discomfort & $38 \pm 18.5$ & $31 \pm 19.2$ & ns \\
\hline NA & $1(3)$ & 0 & - \\
\hline
\end{tabular}

Values are shown as mean \pm standard deviation or $n(\%)$. ns, not significant; NA, no answer.

Table 3. Correlation between the self-assessment questionnaires stratified by cognitive status

\begin{tabular}{llllll}
\hline Assessment & $\begin{array}{l}\text { Cognitive } \\
\text { status }\end{array}$ & BDI & BAI & OCI-R & SRMI \\
\hline PDQ-39SI & MCI & 0.53 & $0.72^{*}$ & $0.78^{*}$ & 0.56 \\
& Non-MCI & $0.61^{*}$ & $0.66^{*}$ & $0.53^{*}$ & $0.6^{*}$ \\
\hline SRMI & MCI & 0.1 & 0.29 & 0.59 & $0.6^{*}$ \\
\hline OCI-R & Non-MCI & 0.43 & $0.59^{*}$ & & \\
& MCI & 0.19 & 0.32 & & \\
\hline BAI & Non-MCI & 0.22 & $0.51^{*}$ & & \\
& MCI & 0.6 & & & \\
\hline
\end{tabular}

$* p \leq 0.01$. 
Table 4. Correlations between the confounding factors and the psychological assessments, stratified by patients with and those without MCI

\begin{tabular}{lllllllrr}
\hline Assessment & $\begin{array}{l}\text { Cognitive } \\
\text { status }\end{array}$ & $\begin{array}{l}\text { Gender } \\
\text { (male) }\end{array}$ & Age & Education & $\begin{array}{l}\text { Disease } \\
\text { duration }\end{array}$ & \multicolumn{1}{l}{$\begin{array}{l}\text { UPDRS } \\
\text { III }\end{array}$} & MMSE & LEDD \\
\hline BDI & MCI & -0.25 & 0.16 & -0.06 & -0.30 & -0.21 & 0.09 & -0.17 \\
& Non-MCI & -0.33 & -0.02 & 0.05 & 0.25 & 0.29 & -0.07 & 0.03 \\
\hline BAI & MCI & -0.09 & 0 & 0.03 & 0.12 & 0.33 & 0.19 & 0.10 \\
& Non-MCI & -0.34 & -0.12 & -0.16 & 0.31 & 0.28 & 0.09 & -0.01 \\
\hline OCI-R & MCI & 0.14 & 0.38 & -0.07 & 0.25 & 0.26 & -0.20 & -0.14 \\
& Non-MCI & 0.04 & 0.06 & -0.03 & -0.14 & 0.03 & -0.20 & 0.11 \\
\hline SRMI & MCI & 0.00 & 0 & 0.08 & 0.39 & 0.16 & -0.11 & 0.48 \\
& Non-MCI & -0.06 & -0.24 & -0.01 & -0.04 & -0.01 & 0.03 & 0.28 \\
\hline PDQ-39SI & MCI & -0.03 & 0.16 & 0.04 & 0.17 & 0.25 & 0.17 & 0.09 \\
& Non-MCI & -0.23 & -0.08 & -0.09 & 0.40 & -0.01 & -0.20 & 0.33 \\
\hline
\end{tabular}

Table 5. Multivariate regression analysis of the influence on quality of life

\begin{tabular}{lcccc}
\hline Influence factors & Estimate & Standard error & $t$ value & $p$ value \\
\hline MCI (vs. non-MCI) & 4.50 & 1.93 & 2.33 & $0.03^{*}$ \\
BDI & 0.87 & 0.25 & 3.46 & $\leq 0.01^{* *}$ \\
BAI & 0.54 & 0.17 & 3.14 & $\leq 0.01^{* *}$ \\
SRMI & 0.52 & 0.27 & 1.91 & 0.06 \\
Age & 0.28 & 0.12 & 2.24 & $0.03^{*}$ \\
Disease duration & 0.38 & 0.21 & 1.79 & 0.08 \\
UPDRS III & -0.12 & 0.08 & -1.44 & 0.16 \\
LEDD & 0.00 & 0.00 & 1.51 & 0.14 \\
\hline
\end{tabular}

$R^{2}=0.68{ }^{*} \mathrm{p} \leq 0.5 ;{ }^{* *} \mathrm{p} \leq 0.01$.

\section{Confounding Factors and Their Correlations with NPS}

Table 4 shows the correlations of the self-assessment questionnaires with the confounding factors. There are 2 significant positive correlations in the non-MCI cohort: between PDQ-39SI and disease duration and between BAI and gender. After correction for multiple testing, there were no significant correlations between the questionnaires and the confounding factors.

Difference in the Subscales of the PDQ-39 and the Summary Index Regarding the Cognitive Status

Figure 1 shows the differences between the patients with and without MCI in the PDQ39-SI and the subscales. As the $p$ values illustrate, there are no significant differences between patients with and those without MCI. Before correction for multiple testing, there was 1 significant correlation between stigma and cognitive status.

\section{Regression Analysis}

Table 5 shows the regression analysis with the influences on QoL. The significant model (adjusted $\left.R^{2}=0.68, p \leq 0.01\right)$ revealed significant influences of $\operatorname{MCI}(p=0.03)$, BDI $(p \leq 0.01)$, BAI $(p \leq 0.01)$, age $(p=0.03)$, a trend of SRMI $(p=0.06)$, and disease duration $(p=0.08)$. 


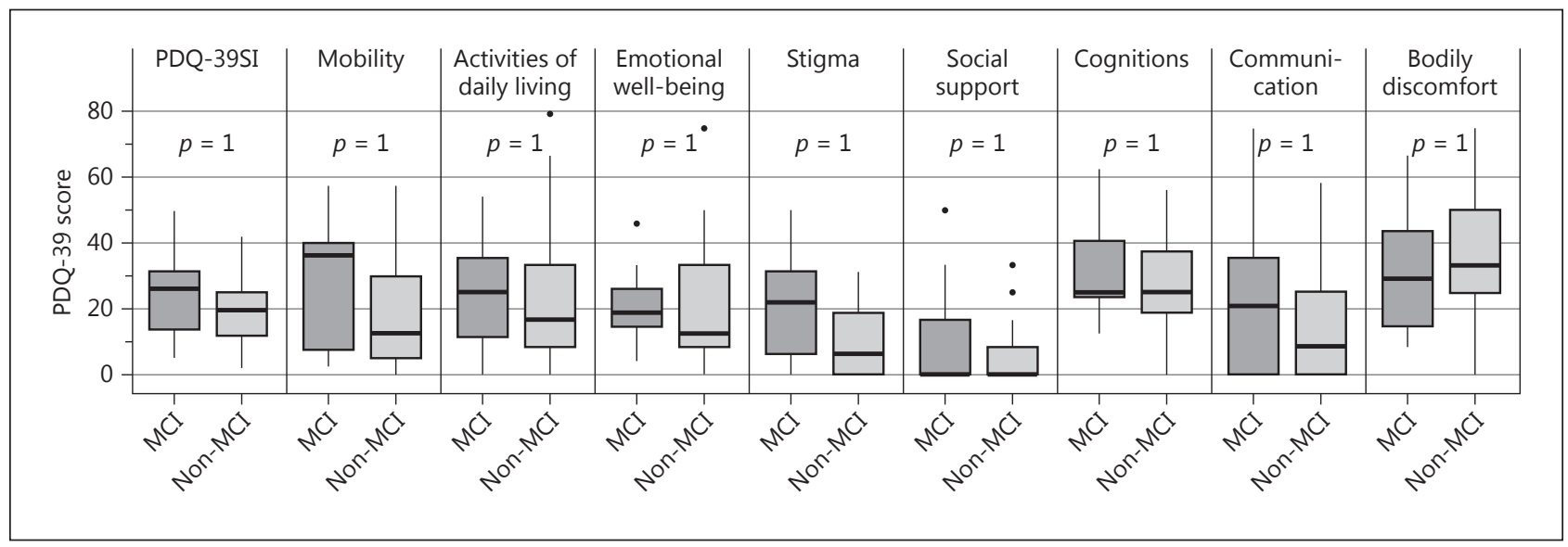

Fig. 1. Eight dimensions and summary index (SI) of the PDQ-39 with mean and SD.

Fig. 2. Explained variance of qual-

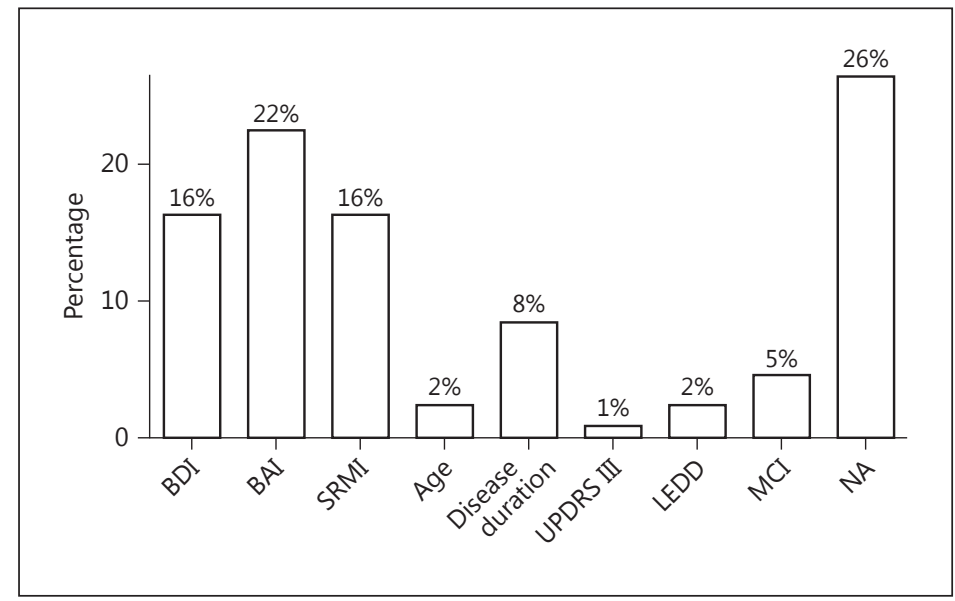
ity of life.

Furthermore, UPDRS III and LEDD were not significant in the prediction of QoL but remained in the model according to AIC. The variables education, OCI-R, and gender dropped out from the linear regression model. Figure 2 displays the relative importance of the predictors: it shows that QoL in PD was mostly explained by NPS measurements, whereas sample- and disease-related factors were less important.

\section{Discussion}

In our study we showed that QoL in PD is influenced by anxiety, depression, MCI, and age. Our results confirm that NPS in association with MCI decrease QoL. QoL is mainly decreased by NPS, whereas the cognitive status is of minor importance. Mania and disease duration may further reduce QoL. Multiple studies show a relation between cognitive functions and QoL [51-54]. Depression and anxiety have been reported to be strong factors in terms of a decrease in QoL [55-62]. Thus, our results are in line with these findings, except for the influence of anxiety and depression on QoL. One study showed the reverse, in that depression may be the 
predominant factor for a low QoL compared to anxiety [57]. More interestingly, in our study, a significant effect of age on QoL has been found. Although other studies reported age to be no cause of a decrease in QoL [63-65], these studies have eliminated the factor age in their analysis due to having it as an exclusion criterion for their sample [66]. Thus, the true effect of age may have been overlooked in the first place. In contrast, our study contains a wide range of ages (i.e., ranging from 46 up to 84 years), which - in turn - may provide enough variance to calculate its true significance in the computed linear regression model. However, according to the relative importance in Figure 2, age does not seem to have a strong influence on QoL.

In this study, the disease duration was not significantly associated with a lower QoL. Yet, previously, disease duration has been understood as a predictor for a poorer QoL [63, 64, 67]; whereas in other studies disease duration was not significantly involved in their statistical analysis $[65,68]$. In our study we had a higher disease duration within the sample compared to other studies $[63,64,67]$ and lower than in the studies, which could not affirm a significant involvement of disease duration on the QoL $[65,68]$. Possibly, disease duration loses its role as a predictor over time. Figure 2 shows that the relative importance of disease duration for QoL is low with about 8\%.

OCI-R, education, and gender have been eliminated within the linear regression model. According to another study, OCD decreases QoL. However, in this study the authors explained that the self-assessment questionnaire they used did not allow an accurate differentiation between pathological and normal behaviors [69]. Further limitations are that QoL is a generic measurement, whereas the current living situation of OCD patients cannot be fully captured via normal QoL questionnaires [70]. The influence of education and gender on QoL remains debatable. First turning to gender, there is a study that showed a significant negative influence on QoL of female participants. However, the sample was not well balanced with a female to male gender ratio of 60 to 218 [61]. As a fact, other studies could not replicate this influence $[56,64,65,71]$. In terms of education, the literature is yet to agree on its role in QoL $[64,65$, 72]. However, unquestioned remains the fact that education has a protective effect on cognitive functions [72-74].

In regards to BDI, we have a representative sample of patients with mild depression and patients suffering from mild to more severe anxiety levels in comparison to other studies (i.e., depression studies [75-77]; anxiety studies [78-81]). The relationship between depression and anxiety has been examined in other studies [80-82]. However, most importantly, the BAI is not the most valuable tool for screening anxiety in PD. The literature suggests that a more suitable test for screening anxiety in PD is required [83, 84].

It could be shown that the result of the SRMI is not dependent on self-awareness [39]. This fact is very important for the adoption of a self-assessment questionnaire, since mania is often accompanied by anosognosia. The present study included 3 patients with mania (according to the SRMI) at the day of examination and mania still decreased the QoL, which is not common. In the presence of the typical symptoms, patients are more likely to be cheerful than in a bad mood. Thus, SRMI remained as a predictor variable in our model, due to the possible relationship between depression and mania in bipolar disorder and anxiety [85-87]. OCD also has a correlation with anxiety [88]. Yet, explaining the correlations between the different NPS measurements as in Table 3 is particularly difficult. At this point, it may be suggested that the correlation between depression and anxiety does not depend on the cognitive status. However, the cognitive status has an effect on the correlations between anxiety and OCD, anxiety and depression, anxiety and mania as well as OCI and mania. There were no significant correlations for the MCI patients. MCI may possibly override any relationships amongst other NPS. 
There was no correlation between LEDD and mania in our data in contrast to the findings of previous studies [89]. Furthermore, no significant involvement of LEDD in QoL was found in our model which is also not consistent with the literature [60,61]. Maybe this finding is linked to the fact that the levodopa doses the patients received were fine-tuned, so they did not have Parkinson symptoms and also did not have much adverse reaction.

In our sample we had lower PDQ-39 scores as comparable studies [57, 65, 72, 90, 91], which may be attributable to a good medical care and good living standard.

Not all of the mentioned studies did use the questionnaires we did for this study. Some adopted the DSM-III or the DSM-IV criteria to diagnose depression, anxiety, OCD, and mania, whereas other studies used different self-reporting questionnaires like the Hospital Anxiety and Depression Scale (HADS) [92, 93] or the Hamilton Anxiety Rating Scale (HARS) [94, 95]. This might be a reason for the inconsistent findings between QoL and NPS over different studies.

However, self-assessment questionnaires are very practical, they give a comprehensive overview of the presence or absence of neuropsychiatric impairments. The advantage in this study is that we screened in an extended way for depression, anxiety, and mania and gathered the level of QoL in a more exact way. Moreover, we examined the influence from NPS in association with MCI on QoL.

Our results imply that NPS has a much greater effect on QoL in PD in comparison to cognitive status. According to Figure 2, the relative importance of MCI in QoL is only about $5 \%$, whereas the influence of NPS is over $50 \%$. Thus, this underlines the importance to screen for depression and anxiety in PD in order to adjust further therapy procedures. The 4 NPS (i.e., depression, anxiety, OCD, and mania) appear to be interconnected; however, the nature of the relationship is yet to be understood in full.

\section{Acknowledgements}

We would like to thank all participants as well as Parkinson Schweiz, the Gossweiler Foundation, the Freiwillige Akademische Gesellschaft Basel, and the Bangerter-Rhyner Foundation for supporting this study. The study was primarily funded by Parkinson Schweiz, the Gossweiler Foundation, the Freiwillige Akademische Gesellschaft Basel, and the BangerterRhyner Foundation.

\section{Disclosure Statement}

None of the authors have any conflicts of interest.

\section{References}

$>1$ Chaudhuri KR, Healy DG, Schapira AH: Non-motor symptoms of Parkinson's disease: diagnosis and management; Lancet Neurol 2006;5:235-245.

$>2$ Rana AQ, Ahmed US, Chaudry ZM, Vasan S: Parkinson's disease: a review of non-motor symptoms. Expert Rev Neurother 2015;15:549-562.

-3 Crosiers D, Pickut B, Theuns J, Deyn PP, Van Broeckhoven C, Martinez-Martin P, Chaudhuri KR, Cras P: Nonmotor symptoms in a Flanders-Belgian population of 215 Parkinson's disease patients as assessed by the NonMotor Symptoms Questionnaire. Am J Neurodegener Dis 2012;1:160-167.

4 Li H, Zhang M, Chen L, Zhang J, Pei Z, Hu A, Wang Q: Nonmotor symptoms are independently associated with impaired health-related quality of life in Chinese patients with Parkinson's disease. Mov Disord 2010;25: 2740-2746. 
5 Barone P, Antonini A, Colosimo C, Marconi R, Morgante L, Avarello TP, Bottacchi E, Cannas A, Ceravolo G, Ceravolo R, Cicarelli G, Gaglio RM, Giglia RM, Iemolo F, Manfredi M, Meco G, Nicoletti A, Pederzoli M, Petrone A, Pisani A, Pontieri FE, Quatrale R, Ramat S, Scala R, Volpe G, Zappulla S, Bentivoglio AR, Stocchi F, Trianni G, Dotto PD; The PRIAMO study: A multicenter assessment of nonmotor symptoms and their impact on quality of life in Parkinson's disease. Mov Disord 2009;24:1641-1649.

6 Martinez-Martin P, Rodriguez-Blazquez C, Kurtis MM, Chaudhuri KR: The impact of non-motor symptoms on health-related quality of life of patients with Parkinson's disease. Mov Disord 2011;26:399-406.

7 Erro R, Picillo M, Vitale C, Amboni M, Moccia M, Santangelo G, Pellecchia MT, Barone P: The non-motor side of the honeymoon period of Parkinson's disease and its relationship with quality of life: a 4-year longitudinal study. Eur J Neurol 2016;23:1673-1679.

-8 Pandey S, Bajaj BK, Wadhwa A, Anand KS: Impact of sleep quality on the quality of life of patients with Parkinson's disease: a questionnaire based study. Clin Neurol Neurosurg 2016;148:29-34.

-9elsh M: Parkinson's disease and quality of life: issues and challenges beyond motor symptoms. Neurol Clin 2004;22:S141-S148.

10 Schenkman M, Wei Zhu C, Cutson TM, Whetten-Goldstein K: Longitudinal evaluation of economic and physical impact of Parkinson's disease. Parkinsonism Relat Disord 2001;8:41-50.

11 Masuhr KF: Neurologie; in Neumann M (ed): Duale Reihe, Stuttgart : Thieme.

12 Chaudhuri KR, Schapira AH: Non-motor symptoms of Parkinson's disease: dopaminergic pathophysiology and treatment; Lancet Neurol 2009;8:464-474.

13 Dilling H (ed): Internationale Klassifikation psychischer Störungen: ICD-10 Kapitel V (F): Klinisch-diagnostische Leitlinien. Bern, Huber, 2011, pp 159-163, 169-200.

14 Leentjens AF: Depression in Parkinson's disease: conceptual issues and clinical challenges. J Geriatr Psychiatry Neurol 2004;17:120-126.

15 Kuopio AM, Marttila RJ, Helenius H, Toivonen M, Rinne UK: The quality of life in Parkinson's disease. Mov Disord 2000;15:216-223.

16 Phillips P: Keeping depression at bay helps patients with Parkinson disease. JAMA 1999;282:1118-1119.

17 McDonald WM, Richard IH, DeLong MR: Prevalence, etiology, and treatment of depression in Parkinson's disease. Biol Psychiatry 2003;54:363-375.

18 Slaughter JR, Slaughter KA, Nichols D, Holmes SE, Martens MP: Prevalence, clinical manifestations, etiology, and treatment of depression in Parkinson's disease. J Neuropsychiatry Clin Neurosci 2001;13:187-196.

19 Liu CY, Wang SJ, Fuh JL, Lin CH, Yang YY, Liu HC: The correlation of depression with functional activity in Parkinson's disease. J Neurol 1997;244:493-498.

20 Troster AI, Paolo AM, Lyons KE, Glatt SL, Hubble JP, Koller WC: The influence of depression on cognition in Parkinson's disease: a pattern of impairment distinguishable from Alzheimer's disease. Neurology 1995;45:672-676.

-21 Aarsland D, Larsen JP, Karlsen K, Lim NG, Tandberg E: Mental symptoms in Parkinson's disease are important contributors to caregiver distress. Int J Geriatr Psychiatry 1999;14:866-874.

22 Menza MA, Robertson-Hoffman DE, Bonapace AS: Parkinson's disease and anxiety: comorbidity with depression. Biol Psychiatry 1993;34:465-470.

23 Richard IH: Anxiety disorders in Parkinson's disease. Adv Neurol 2005;96:42-55.

24 Shiba M, Bower JH, Maraganore DM, McDonnell SK, Peterson BJ, Ahlskog JE, Schaid DJ, Rocca WA: Anxiety disorders and depressive disorders preceding Parkinson's disease: a case-control study. Mov Disord 2000;15: 669-677.

25 Weisskopf MG, Chen H, Schwarzschild MA, Kawachi I, Ascherio A: Prospective study of phobic anxiety and risk of Parkinson's disease. Mov Disord 2003;18:646-651.

26 Aarsland D, Andersen K, Larsen JP, Lolk A, Kragh-Sorensen P: Prevalence and characteristics of dementia in Parkinson disease: an 8-year prospective study. Arch Neurol 2003;60:387-392.

27 Janvin C, Aarsland D, Larsen JP, Hugdahl K: Neuropsychological profile of patients with Parkinson's disease without dementia. Dement Geriatr Cogn Disord 2003;15:126-131.

28 Williams-Gray CH, Foltynie T, Brayne CE, Robbins TW, Barker RA: Evolution of cognitive dysfunction in an incident Parkinson's disease cohort. Brain 2007;130:1787-1798.

29 Poletti M, Frosini D, Pagni C, Baldacci F, Nicoletti V, Tognoni G, Lucetti C, Del Dotto P, Ceravolo R, Bonuccelli U: Mild cognitive impairment and cognitive-motor relationships in newly diagnosed drug-naive patients with Parkinson's disease. J Neurol Neurosurg Psychiatry 2012;83:601-606.

-30 Poletti M, Frosini D, Ceravolo R, Bonuccelli U: Mild cognitive impairment in de novo Parkinson's disease according to movement disorder guidelines. Mov Disord 2012;27:1706; author reply 1707.

-31 Reginold W, Duff-Canning S, Meaney C, Armstrong MJ, Fox S, Rothberg B, Zadikoff C, Kennedy N, Gill D, Eslinger P, Marshall F, Mapstone M, Chou KL, Persad C, Litvan I, Mast B, Tang-Wai D, Lang AE, Marras C: Impact of mild cognitive impairment on health-related quality of life in Parkinson's disease. Dement Geriatr Cogn Disord 2013;36:67-75.

-32 Monastero R, Di Fiore P, Ventimiglia GD, Camarda R, Camarda C: The neuropsychiatric profile of Parkinson's disease subjects with and without mild cognitive impairment. J Neural Transm (Vienna) 2013;120:607-611.

-33 Wang YQ, Tang BS, Yan XX, Chen ZH, Xu Q, Liu ZH, Li K, Wang K, Guo JF: A neurophysiological profile in Parkinson's disease with mild cognitive impairment and dementia in China. J Clin Neurosci 2015;22:981-985.

-34 Gibb WR, Lees AJ: The relevance of the Lewy body to the pathogenesis of idiopathic Parkinson's disease. J Neurol Neurosurg Psychiatry 1988;51:745-752. 
-35 Zimmermann R, Gschwandtner U, Benz N, Hatz F, Schindler C, Taub E, Fuhr P: Cognitive training in Parkinson disease: cognition-specific vs nonspecific computer training. Neurology 2014;82:1219-1226.

36 Beck AT, Hautzinger M, Steer RA: Beck-Depressions-Inventar (BDI), ed 2, überarb. Aufl., 1995.

37 Beck AT, Epstein N, Brown G, Steer RA: An inventory for measuring clinical anxiety: psychometric properties. J Consult Clin Psychol 1988;56:893-897.

-38 Foa EB, Huppert JD, Leiberg S, Langner R, Kichic R, Hajcak G, Salkovskis PM: The Obsessive-Compulsive Inventory: development and validation of a short version. Psychol Assess 2002;14:485-496.

-39 Braunig P, Shugar G, Kruger S: An investigation of the Self-Report Manic Inventory as a diagnostic and severity scale for mania; Compr Psychiatry 1996;37:52-55.

40 Shugar G, Schertzer S, Toner BB, Di Gasbarro I: Development, use, and factor analysis of a self-report inventory for mania. Compr Psychiatry 1992;33:325-331.

-41 Peto V, Jenkinson C, Fitzpatrick R: PDQ-39:a review of the development, validation and application of a Parkinson's disease quality of life questionnaire and its associated measures. J Neurol 1998;245(suppl 1):S10-S14.

-42 Peto V, Jenkinson C, Fitzpatrick R, Greenhall R: The development and validation of a short measure of functioning and well being for individuals with Parkinson's disease. Qual Life Res 1995;4:241-248.

43 Jenkinson C, Fitzpatrick R, Peto V, Greenhall R, Hyman N: The Parkinson's Disease Questionnaire (PDQ-39): development and validation of a Parkinson's disease summary index score. Age Ageing 1997;26:353-357.

-44 Litvan I, Goldman JG, Troster AI, Schmand BA, Weintraub D, Petersen RC, Mollenhauer B, Adler CH, Marder K, Williams-Gray CH, Aarsland D, Kulisevsky J, Rodriguez-Oroz MC, Burn DJ, Barker RA, Emre M: Diagnostic criteria for mild cognitive impairment in Parkinson's disease: Movement Disorder Society Task Force guidelines. Mov Disord 2012;27:349-356.

-45 Tomlinson CL, Stowe R, Patel S, Rick C, Gray R, Clarke CE: Systematic review of levodopa dose equivalency reporting in Parkinson's disease. Mov Disord 2010;25:2649-2653.

46 Fahn S, Marsden C, Calne D, Goldstein M: Unified Parkinson's disease scale - UPDRS; in Fahn S, Marsden CD, Calne DB, Goldstein M (eds): Recent Developments in Parkinson's Disease, ed 2. Florham Park, Macmillan Health Care Information, 1987, pp 153-163, 293-304.

-47 Folstein MF, Folstein SE, McHugh PR: "Mini-mental state". A practical method for grading the cognitive state of patients for the clinician. J Psychiatr Res 1975;12:189-198.

48 RStudio Team: RStudio: Integrated Development for R. RStudio, Inc., Boston, 2015.

49 Venables WN, Ripley BD: Modern applied statistics with S. New York, Springer Science+Business Media, 2002.

50 Grömping U: Relative importance for linear regression in R: the package relaimpo. J Stat Softw 2006;17:1-27.

51 Weintraub D, Simuni T, Caspell-Garcia C, Coffey C, Lasch S, Siderowf A, Aarsland D, Barone P, Burn D, Chahine LM, Eberling J, Espay AJ, Foster ED, Leverenz JB, Litvan I, Richard I, Troyer MD, Hawkins KA: Cognitive performance and neuropsychiatric symptoms in early, untreated Parkinson's disease. Mov Disord 2015;30:919927.

52 Lawson RA, Yarnall AJ, Duncan GW, Breen DP, Khoo TK, Williams-Gray CH, Barker RA, Collerton D, Taylor JP, Burn DJ: Cognitive decline and quality of life in incident Parkinson's disease: the role of attention. Parkinsonism Relat Disord 2016;27:47-53.

-53 Lawson RA, Yarnall AJ, Duncan GW, Khoo TK, Breen DP, Barker RA, Collerton D, Taylor JP, Burn DJ: Severity of mild cognitive impairment in early Parkinson's disease contributes to poorer quality of life. Parkinsonism Relat Disord 2014;20:1071-1075.

54 Leroi I, McDonald K, Pantula H, Harbishettar V: Cognitive impairment in Parkinson disease: impact on quality of life, disability, and caregiver burden. J Geriatr Psychiatry Neurol 2012;25:208-214.

55 McKinlay A, Grace RC, Dalrymple-Alford JC, Anderson T, Fink J, Roger D: A profile of neuropsychiatric problems and their relationship to quality of life for Parkinson's disease patients without dementia. Parkinsonism Relat Disord 2008;14:37-42.

56 Carod-Artal FJ, Ziomkowski S, Mourao Mesquita H, Martinez-Martin P: Anxiety and depression: main determinants of health-related quality of life in Brazilian patients with Parkinson's disease. Parkinsonism Relat Disord 2008;14:102-108.

57 Rahman S, Griffin HJ, Quinn NP, Jahanshahi M: Quality of life in Parkinson's disease: the relative importance of the symptoms. Mov Disord 2008;23:1428-1434.

58 Slawek J, Derejko M, Lass P: Factors affecting the quality of life of patients with idiopathic Parkinson's disease: a cross-sectional study in an outpatient clinic attendees. Parkinsonism Relat Disord 2005;11:465-468.

59 Factors impacting on quality of life in Parkinson's disease: results from an international survey. Mov Disord 2002;17:60-67.

60 Karlsen KH, Larsen JP, Tandberg E, Maeland JG: Influence of clinical and demographic variables on quality of life in patients with Parkinson's disease. J Neurol Neurosurg Psychiatry 1999;66:431-435.

-61 Behari M, Srivastava AK, Pandey RM: Quality of life in patients with Parkinson's disease. Parkinsonism Relat Disord 2005;11:221-226.

62 Schrag A, Jahanshahi M, Quinn N: What contributes to quality of life in patients with Parkinson's disease? J Neurol Neurosurg Psychiatry 2000;69:308-312.

63 Lyons KE, Pahwa R, Troster AI, Koller WC: A comparison of Parkinson's disease symptoms and self-reported functioning and well being. Parkinsonism Relat Disord 1997;3:207-209.

64 Zhao YJ, Tan LC, Lau PN, Au WL, Li SC, Luo N: Factors affecting health-related quality of life amongst Asian patients with Parkinson's disease. Eur J Neurol 2008;15:737-742. 
Klepac N, Pikija S, Kraljic T, Relja M, Trkulja V, Juren S, Pavlicek I, Babic T: Association of rural life setting and poorer quality of life in Parkinson's disease patients: a cross-sectional study in Croatia. Eur J Neurol 2007;14: 194-198.

66 Soh SE, Morris ME, McGinley JL: Determinants of health-related quality of life in Parkinson's disease: a systematic review. Parkinsonism Relat Disord 2011;17:1-9.

67 Michalowska M, Fiszer U, Krygowska-Wajs A, Owczarek K: Falls in Parkinson's disease. Causes and impact on patients' quality of life. Funct Neurol 2005;20:163-168.

68 Zach M, Friedman A, Slawek J, Derejko M: Quality of life in Polish patients with long-lasting Parkinson's disease. Mov Disord 2004;19:667-672.

69 Phu AL, Xu Z, Brakoulias V, Mahant N, Fung VS, Moore GD, Martin A, Starcevic V, Krause M: Effect of impulse control disorders on disability and quality of life in Parkinson's disease patients. J Clin Neurosci 2014;21: 63-66.

70 Hauschildt M, Jelinek L, Randjbar S, Hottenrott B, Moritz S: Generic and illness-specific quality of life in obsessive-compulsive disorder. Behav Cogn Psychother 2010;38:417-436.

71 Carod-Artal FJ, Vargas AP, Martinez-Martin P: Determinants of quality of life in Brazilian patients with Parkinson's disease. Mov Disord 2007;22:1408-1415.

-72 Cubo E, Rojo A, Ramos S, Quintana S, Gonzalez M, Kompoliti K, Aguilar M: The importance of educational and psychological factors in Parkinson's disease quality of life. Eur J Neurol 2002;9:589-593.

73 Valenzuela MJ, Sachdev P: Brain reserve and dementia: a systematic review. Psychol Med 2006;36:441-454.

-74 Treves TA, Parmet Y, Klimovitzky S, Korczyn AD: The effect of schooling on reported age of onset of cognitive decline: a collaborative study. J Clin Neurosci 2016;34:86-88.

75 Cummings JL: Depression and Parkinson's disease: a review. Am J Psychiatry 1992;149:443-454.

76 Burn DJ: Beyond the iron mask: towards better recognition and treatment of depression associated with Parkinson's disease. Mov Disord 2002;17:445-454.

77 Veazey C, Aki SO, Cook KF, Lai EC, Kunik ME: Prevalence and treatment of depression in Parkinson's disease. J Neuropsychiatry Clin Neurosci 2005;17:310-323.

78 Broen MP, Narayen NE, Kuijf ML, Dissanayaka NN, Leentjens AF: Prevalence of anxiety in Parkinson's disease: a systematic review and meta-analysis. Mov Disord 2016;31:1125-1133.

-79 Rutten S, Ghielen I, Vriend C, Hoogendoorn AW, Berendse HW, Leentjens AF, van der Werf YD, Smit JH, van den Heuvel OA: Anxiety in Parkinson's disease: symptom dimensions and overlap with depression and autonomic failure. Parkinsonism Relat Disord 2015;21:189-193.

-80 Leentjens AF, Dujardin K, Marsh L, Martinez-Martin P, Richard IH, Starkstein SE: Symptomatology and markers of anxiety disorders in Parkinson's disease: a cross-sectional study. Mov Disord 2011;26:484-492.

-81 Prediger RD, Matheus FC, Schwarzbold ML, Lima MM, Vital MA: Anxiety in Parkinson's disease: a critical review of experimental and clinical studies. Neuropharmacology 2012;62:115-124.

-82 Dissanayaka NN, Sellbach A, Matheson S, O’Sullivan JD, Silburn PA, Byrne GJ, Marsh R, Mellick GD: Anxiety disorders in Parkinson's disease: prevalence and risk factors. Mov Disord 2010;25:838-845.

83 Leentjens AF, Dujardin K, Marsh L, Richard IH, Starkstein SE, Martinez-Martin P: Anxiety rating scales in Parkinson's disease: a validation study of the Hamilton anxiety rating scale, the Beck anxiety inventory, and the hospital anxiety and depression scale. Mov Disord 2011;26:407-415.

84 Forjaz MJ, Martinez-Martin P, Dujardin K, Marsh L, Richard IH, Starkstein SE, Leentjens AF: Rasch analysis of anxiety scales in Parkinson's disease. J Psychosom Res 2013;74:414-419.

85 Pavlova B, Perroud N, Cordera P, Uher R, Dayer A, Aubry JM: Childhood maltreatment and comorbid anxiety in people with bipolar disorder. J Affect Disord 2016;192:22-27.

86 Perugi G, Akiskal HS, Toni C, Simonini E, Gemignani A: The temporal relationship between anxiety disorders and (hypo)mania: a retrospective examination of 63 panic, social phobic and obsessive-compulsive patients with comorbid bipolar disorder. J Affect Disord 2001;67:199-206.

87 Pavlova B, Perlis RH, Alda M, Uher R: Lifetime prevalence of anxiety disorders in people with bipolar disorder: a systematic review and meta-analysis. Lancet Psychiatry 2015;2:710-717.

-88 Nestadt G, Samuels J, Riddle MA, Liang KY, Bienvenu OJ, Hoehn-Saric R, Grados M, Cullen B: The relationship between obsessive-compulsive disorder and anxiety and affective disorders: results from the Johns Hopkins OCD Family Study. Psychol Med 2001;31:481-487.

-89 Maier F, Merkl J, Ellereit AL, Lewis CJ, Eggers C, Pedrosa DJ, Kalbe E, Kuhn J, Meyer TD, Zurowski M, Timmermann L: Hypomania and mania related to dopamine replacement therapy in Parkinson's disease. Parkinsonism Relat Disord 2014;20:421-427.

90 Gomez-Esteban JC, Zarranz JJ, Lezcano E, Tijero B, Luna A, Velasco F, Rouco I, Garamendi I: Influence of motor symptoms upon the quality of life of patients with Parkinson's disease. Eur Neurol 2007;57:161-165.

-91 Chapuis S, Ouchchane L, Metz O, Gerbaud L, Durif F: Impact of the motor complications of Parkinson's disease on the quality of life. Mov Disord 2005;20:224-230.

92 Zigmond AS, Snaith RP: The hospital anxiety and depression scale. Acta Psychiatr Scand 1983;67:361-370.

-93 Marinus J, Leentjens AF, Visser M, Stiggelbout AM, van Hilten JJ: Evaluation of the hospital anxiety and depression scale in patients with Parkinson's disease. Clin Neuropharmacol 2002;25:318-324.

-94 Hamilton M: The assessment of anxiety states by rating. Br J Med Psychol 1959;32:50-55.

-95 Forjaz MJ, Rodriguez-Blazquez C, Martinez-Martin P: Rasch analysis of the hospital anxiety and depression scale in Parkinson's disease. Mov Disord 2009;24:526-532. 